\title{
DIÁLOGOS SOBRE FORMAÇÃO HUMANA E EDUCAÇÃO SOCIALISTA: MAKARENKO E PISTRAK
}

Lucíola Andrade Maia ${ }^{1}$

\section{Resumo}

Este texto discute a educação socialista abordando especialmente a formação humana sob o signo do socialismo, tomando como exemplo a experiência soviética do início do século XX. Apoiada, maiormente em Makarenko e Pistrak, a discussão apresenta o par dialético indivíduo-coletividade como uma expressão das possibilidades humanas de superar as contradições inerentes à alienação da sociedade capitalista. Nessa perspectiva, debate a formação do novo homem, identificado com o socialismo. Fundamentada em Lênin, a argumentação compreende que a educação que se pretende apolítica, demonstra-se conservadora, portanto, avessa aos compromissos sociais e ao sentido revolucionário da práxis humana.

Palavras-chaves: Educação, Práxis, Novo homem, Socialismo.

\begin{abstract}
:
This text discusses the socialist education, especially broaching human development under the aegis of socialism, taking as example the Soviet experience from the early twentieth century. Based essentially on Makarenko and Pistrak, this discussion presents the dialectic dichotomy individual-community as an expression of the human abilities to overcome contradictions inherent in the alienation produced by capitalist society. In this perspective, it debates the formation of the new man, identified with Socialism. The line of argument is grounded on Lenin's thoughts and it understands that the nonpolitical education which is intended tends to be conservative, therefore, it is incompatible with social commitment and the revolutionary sense of the human praxis.
\end{abstract}

Keywords: Education, Praxis, New man, Socialism.

\footnotetext{
"Quando o homem estiver compreendido na estrutura da realidade e a realidade for entendida como totalidade de natureza e história, serão criados os pressupostos para a solução da problemática filosófica do homem. Se a realidade é incompleta sem o homem, também o homem é igualmente fragmentário sem a realidade. Não se pode conhecer a natureza do homem na antropologia filosófica, a qual encerra o homem na subjetividade da consciência, da raça, da sociabilidade e o separa radicalmente do universo." (Karel Kosik).
}

\footnotetext{
${ }^{1}$ Professora da Universidade Estadual do Ceará, Centro de Educação, curso de Pedagogia. Doutora em Educação Brasileira pela Universidade Federal do Ceará. Coordenadora na UECE das pesquisas $A$ obra de Florestan Fernandes, teoria e método: interpretação da realidade brasileira; Florestan Fernandes, Movimentos Sociais e Educação no Brasil; Florestan Fernandes e o Movimento dos Sem Terra -MST.
} 


\section{INTRODUÇÃO}

Este artigo enfoca uma discussão sobre educação socialista, em seu sentido histórico, demarcando especialmente autores partícipes do processo revolucionário e da implantação do sistema educacional soviético no início do século XX, como Makarenko $(1986)^{2}$ e Pistrak (2002). ${ }^{3}$ Realizamos diálogos com esses autores por compreendermos a perspectiva socialista em educação como um processo omnilateral, portanto, rico e diversificado, abrangendo várias atividades humanas.

O objetivo central de nossa discussão é demonstrar a importância da formação do novo homem para a escola, para a universidade, e para a sociedade. Assim, tomamos como paradigma a filosofia socialista, interligando o debate sobre a formação do homem em Makarenko, e o problema da relação indivíduo-coletividade em Pistrak, importantes contribuições históricas para a educação mundial. Na mesma direção, destacamos a colaboração pedagógica e científica de linhagem socialista para as ciências humanas apoiados também em Lênin (1988), Gramsci (1978), (1980) Fromm (1964), Manacorda (2000 a), (2000 b) Fernandes (1995).

Os referidos autores nos orientam ser de fundamental importância no debate acerca da educação e da formação do homem socialista, encetarmos uma conexão entre a educação e o processo de acumulação do capital ${ }^{4}$. Isso nos auxilia a entender as razões estruturais da exclusão social da classe trabalhadora e seus direitos sociais, tópico que não discutiremos a fundo neste texto.

Nossa abordagem considera as desigualdades sociais, dentre elas as educacionais, construções históricas da lógica fundamentada no acúmulo de capital. Nesse processo de acumulação de capital, a classe que vive do trabalho carece de bens essenciais a uma vida material e intelectual digna, como o alto desenvolvimento das forças produtivas demonstram ser possível ocorrer. Portanto, a discussão sobre o

\footnotetext{
${ }^{2}$ Importante pedagogo, liderança e autor marxista russo, lutou para construir um processo de educação revolucionária na União Soviética. Dirigiu a Colônia Maxim Gorki e a Comuna Dzerjinski.

${ }^{3}$ Um dos mais notáveis autores russos em educação, doutor em Ciências Pedagógicas com formação em físico-matemática, trabalhou pela implantação de uma educação marxista na União Soviética. Dirigiu a Escola-Comuna NarKomPros. Foi diretor do Instituto Central de Pesquisa Científica de Pedagogia junto ao instituto Superior Comunista de Educação do Partido Comunista.

${ }^{4}$ Sobre o tópico conferir a teoria detalhada em: MESZÁROS, István. Para Além do Capital. Campinas: Boi Tempo Editorial, 2002. Confira também a obra de MESZÁROS, István. A teoria da Alienação em Marx. São Paulo: Boitempo Editorial, 2003.
} 
homem socialista, suas lutas e seus nexos com a realidade é a centralidade desse texto, o que passamos a desenvolver a seguir.

\title{
1. QUE TIPO DE HOMEM QUEREMOS FORMAR ?
}

Objetivando elaborarmos uma discussão relativamente aos fins sociais e educacionais a se perseguir no mundo contemporâneo e sobre suas consequências a respeito da vida humana sob uma nova forma de organização social, elencamos as seguintes perguntas: Queremos formar um homem individualista, movido pela indústria, pelo consumo e pela robótica, ou um homem que pensa, elabora, luta coletivamente por direitos sociais, pela transformação e emancipação da sociedade? De qual homem a humanidade e a escola necessitam? Quais suas características, quais seus princípios? Quais fundamentos filosóficos-práxicos e de vida esse homem necessita ter?

Intentando responder a essas indagações expostas nos apoiamos em Pistrak (2009) reconhecido escritor russo que elabora importante discussão sobre a referida temática. Em A Escola-Comuna, obra-prima da educação socialista, Pistrak escreve:

\begin{abstract}
Que tipo de homens a fase revolucionária em que vivemos atualmente ( e que será provavelmente muito longa) exige de nós? À pergunta podemos dar a seguinte resposta: A fase que vivemos é uma fase de luta e de construção, construção que se faz por baixo, de baixo para cima, e que só será possível e benéfica na condição em que cada membro da sociedade compreenda claramente o que é preciso construir e como é preciso construir. (PISTRAK, 2002, p. 33).
\end{abstract}

Nessa perspectiva, a indagação de Pistrak expressa sentido nos transportando para reflexões anunciadas no alvor do século XX, período em que ganhavam força as ideias de uma educação socialista. Seus ecos ressoam no século XXI, nos corredores do tempo, seja nas universidades, nas escolas, nos sindicatos, nas avenidas nas quais passaram marchas imortais pela liberdade, nos braços erguidos dos movimentos sociais ${ }^{5}$, seja em mobilizações populares, na tentativa de construção de uma sociedade livre do modo de produção capitalista. Os hinos do socialismo ainda embalam e pintam as bandeiras em lutas por uma nova forma de vida.

O escritor citado continua sua exposição apresentando questões organizativas relevantes para a formação do homem socialista em construção. Ao realçar que o sistema precisa trabalhar nos educadores e no povo os seguintes tópicos como solução

\footnotetext{
5 Vejamos por exemplo a Passeata das Mulheres de pano "rojo" (vermelho) em Madrid em julho de 2011, a Marcha Nacional dos Sem Terra - MST a Brasília em maio de 2005, a gloriosa Passeata dos educadores (em greve) da educação básica do Estado do Ceará no segundo semestre de 2011.
}

\begin{tabular}{|l|l|l|l|l|} 
Revista Dialectus & Ano 1 & n. 1 & Julho-Dezembro 2012 & p. 271-283 \\
\hline
\end{tabular}




\section{DIÁLOGOS SOBRE FORMAÇÃO HUMANA E FORMAÇÃO...}

Lucíola Andrade Maia

para problemas emergenciais de natureza teórica e prática: atributos para trabalhar coletivamente e para encontrar espaço num trabalho coletivo; aptidão para analisar cada problema novo como organizador; disposição e criatividade para criar as condições eficazes de organização. ${ }^{6}$

Relativamente a esta questão, Lênin apresenta importantes contribuições. De acordo com o referido pensador, na linha teórica e prática de enfrentar o desafio de edificar o socialismo é essencial investir na educação do homem, reconstruir o país e sanar os problemas emergenciais em seus diferenciados e múltiplos sentidos. Dessa maneira, relevantes atividades políticas haveriam de ser realizadas: organizar os trabalhadores do campo e da cidade, nas fábricas, no terreno filosófico, fundando uma nova mentalidade internacionalista de homem, seja no âmbito de construir as bases fundamentais do socialismo naquele país em nome da própria sobrevivência e soberania do povo.

Desse modo, Lênin, em 1918, no histórico acontecimento no primeiro Congresso do Ensino na União das Repúblicas Socialistas Soviéticas - URSS, discursava “Em toda a linha da educação, parece-nos impossível conservar a antiga concepção de uma educação apolítica; parece-nos impossível colocar o trabalho cultural fora da política." (LÊNIN, apud PISTRAK, 2002, p. 23). Essa fala implica em dizer que Lênin (1988) defende uma educação politizada diferente da educação domesticadora do capital, caracterizada pela produção mecânica de técnicas e pela dualidade e unilateralidade.

Nesse sentido, Lênin (1988) entende que a escola fora da vida, fora da política, é uma educação apolítica e como a educação e ciência não são neutras, a sociedade não é neutra, não é harmônica como defende o positivismo em seu lema "Ordem e Progresso." Para Lênin, a educação não deve nem pode ser apolítica. Todo ser humano pensa e ao pensar elabora concepções desde a infância até a morte porque, segundo Paracelso. ninguém passa dez horas sem aprender. ${ }^{7}$

Portanto, a compreensão leninista de escola e de educação do ponto de vista das teses do socialismo, imprime uma educação politizada na qual o homem seja crítico e consciente do seu papel social, como homem e pensador socialista. Mais ainda: o homem numa concepção socialista passa a edificar a práxis da coletividade, cooperação,

\footnotetext{
ЂHá importantes e intermináveis tarefas urgentes determinadas pelo governo revolucionário da URSS. naquele período, por exemplo, a reforma agrária.

${ }^{7}$ Cf. MESZÁROS, István. A Educação Para além do Capital. São Paulo: Boitempo Editorial, 2005.
}

\begin{tabular}{|l|l|l|l|l|}
\hline Revista Dialectus & Ano 1 & n. 1 & Julho-Dezembro 2012 & p. 271-283 \\
\hline
\end{tabular}


ativismo e radicalidade da luta e da defesa de uma educação comprometida com o conhecimento científico, técnico, artístico-cultural, pautada na Filosofia da Práxis ${ }^{8}$ transformadora e livre da exploração do capital. Isso ocorre, visando a formação de homens capazes de aprender, ensinar e aplicar, no sentido socialista uma nova "leitura do mundo e da palavra", parafraseando Paulo Freire ${ }^{9}$ em suas obras nas quais advoga a conscientização política das classes populares.

$\mathrm{Na}$ esteira do pensamento leninista a partir de fundamentos socialistas, Florestan Fernandes (1995), ${ }^{10}$ sociólogo e um dos mais notáveis marxistas brasileiros, difusor do ideário socialista na América Latina, sustenta que o homem a se formar é um ser humano engajado nas lutas sociais comprometido com a verdadeira transformação da sociedade em constantes movimentos sociais.

\subsection{A Coletividade Socialista em Makarenko e Pistrak}

Makarenko em meio a inúmeros conflitos da Revolução Russa trabalhando numa situação adversa e com várias linhas de pensamentos pedagógicos, enfrentou os desafios de criar uma nova educação, elaborar métodos inseridos nos princípios socialistas, reconstruir a escola, estabelecer o novo sistema educacional, educar crianças abandonadas.

Nesse percurso pensamos em Makarenko ao ver esse educador imprimir com vigor a pedagogia construída por ele que serviria de base teórica e prática para a educação socialista em várias partes do mundo, inclusive em escolas comandadas por

\footnotetext{
${ }^{8}$ Recomenda-se relevante contribuição sobre o tema elaborado por: Vázquez, Adolfo Sánchez. Filosofia da práxis. Editora Expressão Popular, 2007. "A práxis revolucionária, na análise imediatamente anterior aos manuscritos econômico-filosóficos de 1844, mostra-se em estreita aliança com a filosofia e tendo por sujeito o proletariado como classe destinada a revolucionar a sociedade existente. Vemos aí o proletariado como a expressão concentrada dos sofrimentos que são infligidos ao homem, e impelido a libertar-se, em uma libertação que implica, enquanto tal, sua abolição e a libertação da humanidade inteira." (VÁZQUEZ, 2007, p.120).

${ }^{9}$ Cf. FREIRE, Paulo; MACEDO, Donaldo. Alfabetização: leitura do mundo, leitura da Palavra. Rio de Janeiro: Paz e Terra, 1990. Cf. mais detalhes em FREIRE, Paulo. Conscientização. São Paulo: Moraes, 1980.

${ }^{10}$ Importante referência teórica do socialismo na América Latina, esse autor de cunho universal, aborda em suas obras discussões sobre o tema em pauta. Florestan Fernandes organizou no Brasil, livros sobre o pensamento de Lênin, escreveu o prefácio de Que Fazer? da edição brasileira e proferiu inúmeros discursos a favor de uma educação socialista e dos "debaixo" como ele costumava chamar. Maiores detalhes ver em: FERNANDES. Florestan. Em Busca do Socialismo - últimos escritos e outros textos, São Paulo: Xamã, 1995.
} 
movimentos sociais, a exemplo do MST, referendando a proposta de educação de Makarenko através de suas lutas ${ }^{11}$, no Brasil. Nesse sentido, no dizer de Manacorda:

\begin{abstract}
Makarenko elabora, então uma pedagogia original, anti-rousseauniana e não espontânea, embora toda a literatura pedagógica da época fosse tal, mas voltada para uma exigentíssima "educação dos sentimentos", frequentemente num aparente contraste com os interesses das crianças, assim como elas os entendiam. Esta educação tão exigente se realiza especialmente através da conexão entre instrução e trabalho produtivo, do qual as crianças devem ver os frutos concretos e no qual são necessariamente levadas à colaboração com o objetivo de que são parte. (MANACORDA, 2000, p. 316).
\end{abstract}

Makarenko busca, ao longo de sua vida de educador, formar jovens constantemente envolvidos com a dinâmica social, tendo como meta a edificação e o fortalecimento do socialismo. Esse educador trabalha com uma visão internacionalista de homem e de sociedade, pensando no congraçamento dos povos e na elevação do homem socialista, livre e consciente. O pedagogo socialista ressalta a necessidade da existência de um sistema político internacional que ultrapasse os limites territoriais dos países e desenvolva uma política de alianças da classe operária em âmbito mundial, com o intuito de desenvolver relações políticas entre os povos trabalhadores do mundo, com a finalidade de organizar-se coletivamente pela defesa dos seus direitos sociais e trabalhistas e pela construção de uma consciência de classe internacionalista.

No percurso de sua vida como homem e como educador revolucionário, Makarenko busca subsídios filosóficos nos conceitos gerais de Marx e Engels (1992), os quais veem a educação numa perspectiva dialética como geradora de conhecimento e trabalho. Para Marx e Engels, o saber deve retornar à coletividade sob a forma de tecnologia e de profissionais ricos em conhecimentos interligados ao socialismo. Nesse sentido:

Para educar, os jovens poderão recorrer rapidamente a todo o sistema produtivo, a fim de que possam passar sucessivamente pelos diversos ramos da produção - segundo as diversas necessidades sociais e suas próprias inclinações. (MARX \& ENGELS, 1992, p. 95).

Conforme Maia (2010), Makarenko serve-se dos fundamentos de Marx e Engels para aplicá-los em sua prática político-pedagógica, a exemplo da ênfase na relação entre trabalho e educação nas atividades desenvolvidas na Colônia Maxim Gorki.

No entendimento de Makarenko (1981), (1987), (1991), a formação de um coletivo não é um conjunto de regras que os indivíduos devem seguir sem

\footnotetext{
${ }^{11}$ Sobre a questão do MST ver maiores detalhes em: MAIA, Lucíola Andrade. Mística educação e resistência no movimento dos sem-terra. Fortaleza: Edições UFC, 2008.
}

\begin{tabular}{|l|l|l|l|l|} 
Revista Dialectus & Ano 1 & n. 1 & Julho-Dezembro 2012 & p. 271-283 \\
\hline
\end{tabular}




\section{DIÁLOGOS SOBRE FORMAÇÃO HUMANA E FORMAÇÃO...}

Lucíola Andrade Maia

questionamentos. Para ele, o coletivo de educadores necessita trabalhar em acordo com os princípios práxicos e ideológicos do homem socialista. O trabalho com a coletividade constitui uma das tarefas mais importantes e difíceis do ato pedagógico, compartilhando com o processo de estruturação do novo homem, da formação do espírito coletivo tanto na escola como em toda a sociedade.

A coletividade deve estar presente nas relações sociais, individuais, coletivas, profissionais, considerando a abordagem dos mais diversos problemas nacionais e internacionais. Um dos principais objetivos da coletividade é formar nos homens uma consciência política coerente com os preceitos socialistas. Sobre a disciplina, o aludido escritor explana: "não se pode apresentar nenhuma exigência se não tiver uma coletividade verdadeiramente coesa." (MAKARENKO, 1986, p. 41).

O pedagogo em análise, em sua práxis político-pedagógica, seja em seus escritos, discursos, reuniões e assembleias está sempre preocupado com a formação do homem, com a disciplina e com a coletividade numa compreensão socialista dos educadores e dos educandos. Dentre as principais atividades coletivas realizadas na Colônia Górki, sobrelevamos: trabalhos agrícolas, pecuários; oficinas de mobiliários, oficinas de artes, teatro, música, poesia; jogos e brincadeiras educativas. Ademais, realizavam uma variedade de oficinas criadas de acordo com as necessidades emergenciais exigidas pelo cotidiano.

Sobre as relações na Colônia Górki Maia (2010), na esteira do pensamento makarenkiano expõe que os alunos se espelham nos professores, portanto, os docentes devem ser os mais dedicados possíveis; zelando pelas atividades escolares, não devem ter horários ociosos, sendo importante compartilhar do lazer dos alunos, e participar de todas as atividades importantes envolvendo os educandos. Acerca da temática Makarenko se expressa:

Uma verdadeira coletividade é algo muito difícil. Por isso, se uma pessoa tiver ou não tiver razão, estas questões devem resolver-se não por humor da pessoa ou a favor de interesses particulares, mas atendendo aos interesses da coletividade. Observar sempre a disciplina, cumprir aquilo que é desagradável, mas é indispensável - nisto consiste o elevado sentido de disciplina. (MAKARENKO, 1986, p.41).

Apoiado nesses pressupostos teóricos e práticos, afinados com a filosofia da práxis, a experiência de Makarenko mostra a coletividade no homem socialista primordialmente construída a partir dos princípios políticos filosóficos e ideológicos do marxismo-leninismo. Como o próprio autor escreve em sua obra: 
Como na vida tive que, fundamentalmente resolver objectivos e problemas relacionados com a educação sofri muito com esta questão, quando me enviam educadores sem educação. Gastei vários anos de minha vida e de trabalho, pois é uma grande estupidez contar que um educador sem educação eduque alguém. Considerei que era melhor ter na coletividade quatro educadores talentosos do que 40 sem talento e sem educação. Com meus próprios olhos vi pessoas sem talento e sem educação trabalharem na coletividade. Que resultado poderia dar um trabalho destes? Só a desintegração da coletividade. Não pode haver outros resultados. (MAKARENKO, 1986, p. 101).

Nessa dimensão teórica Makarenko (1989), enfatiza a extrema relevância das experiências da vida coletiva no processo de formação da consciência política do homem e que o coletivo comprometido com as transformações sociais deve ter obrigatoriamente características afinadas com as teses socialistas. Todos os coletivos possuem objetivos teórico-práticos rigorosamente definidos visando a construção de um projeto político maior de superação das velhas estruturas do Império, pois:

o coletivo é um organismo social vivo e, por isso mesmo, possui órgãos, atribuições, responsabilidades, correlações e interdependência entre as partes. Se tudo isso não existe, não há coletivo, há uma simples multidão, uma concentração de indivíduos. (MAKARENKO apud CAPRILES, 1989, p.13).

Portanto, esse modelo makarenkiano de educação e disciplina diferente da educação liberal está ausente nas nossas escolas. Na educação liberal a disciplina privilegia a submissão, a subserviência de forma inconsciente e adestrada. Já a disciplina makarenkiana trabalha a formação e a conscientização política do homem, indicando a necessidade de profundas transformações pretendendo consolidar o novo paradigma teórico educacional em todos os seus aspectos e em todas as áreas do conhecimento.

As obras e os legados sociais de Makarenko (1987) e Pistrak (2009) nos apresentam exemplos de educação, de teoria e de prática nos propondo um pensar e um repensar sobre a temática em debate. Essas reflexões são relevantes e necessárias pois os movimentos sociais abraçam as teorias dos autores citados em suas práticas, educativas, políticas, artísticas, culturais. Por exemplo, no Movimento dos Sem Terra - MST, algumas atividades são fundamentadas nos coletivos, nos destacamentos, nas brigadas revolucionárias descritas por Pistrak e Makarenko, pensando na transformação do homem e da coletividade. 


\section{DIÁLOGOS SOBRE FORMAÇÃO HUMANA E FORMAÇÃO...}

Lucíola Andrade Maia

Daí a importância entre essas conexões teóricas e práticas entre movimentos sociais e educação também advogada por Pistrak em A Escola-Comuna e Fundamentos da Escola do Trabalho:

Os movimentos sociais também ensinam e não porque a escola não entrelaçar-se com eles. Mais ainda: se a escola é necessária, mas insuficiente para produzir muitas das transformações sociais, sua ligação com os movimentos sociais permite potencializar sua ação. (PISTRAK, 2009, p. 93).

É relevante destacarmos que a articulação entre escola, universidade, movimentos sociais (sindicatos, partidos políticos), sociedade é indispensável ao processo de formação humana numa perspectiva socialista. Para a formação de variados coletivos, por exemplo, coletivos de educação física e ginásticas, de educadores, de arte, de cultura, de mobilização, de grupos de estudo em diversas áreas, buscando novos caminhos teóricos e novas aprendizagens.

Na compreensão do educador russo Pistrak, a função de coletivo é atuar como um meio educativo, isto é, "que o ser humano não pode esquecer que existe enquanto indivíduo, que existem as necessidades individuais, coletivas e sociais." (PISTRAK, 2009, p.93).

Nessa direção, Pistrak entende que para a criação de uma coletividade forte deve ser realizado um trabalho articulado com os movimentos sociais, pois estes já desenvolvem práticas políticas coletivistas. Para isso é necessário o homem possuir espírito de luta, de comunidade, de organização, de cooperação, dispor de um vasto conhecimento sobre a realidade do mundo dos homens e fundamentalmente uma práxis solidária.

Aprendendo, este homem, portanto, a definir papéis entre indivíduo e coletividade, pois para se construir um coletivo organizado e comprometido é necessário existir os indivíduos conscientes e em formação de suas claras funções. Desse modo, respeitando e aprimorando as decisões coletivas colocando-as em prática igualmente como definidas pela coletividade em assembleias. Compreendemos que esse processo demanda tempo histórico e a construção do homem em seus múltiplos sentidos e dimensões, inclusive educativas.

Na esteira da elaboração socialista de seu tempo e de seu contexto histórico Pistrak expressa que: “A nova aprendizagem implica assumir que há momentos para o coletivo e há momentos para o indivíduo e que seu desenvolvimento deve colocar estes momentos em uma continuidade dialética." (PISTRAK, 2009, p. 94), pois pensando de

\begin{tabular}{|l|l|l|l|l|} 
Revista Dialectus & Ano 1 & n. 1 & Julho-Dezembro 2012 & p. 271-283 \\
\hline
\end{tabular}




\section{DIÁLOGOS SOBRE FORMAÇÃO HUMANA E FORMAÇÃO...}

Lucíola Andrade Maia

acordo com esse pressuposto teórico, entendemos que a construção do par dialético individual-coletivo é indissolúvel assim como são inseparáveis teoria e prática numa perspectiva do materialismo histórico-dialético.

É essa a intenção de Pistrak ao versar sobre a temática: o coletivo, não deve ser a negação pura e simples do indivíduo, de sua individualidade. Assim o autor advoga que nas práticas políticas e sociais a própria individualidade precisa do coletivo para seu desenvolvimento e aprimoramento, pois "Nem se aprende, nem se luta espontaneamente.” (PISTRAK, 2009, p. 95).

(in) conclusão:

Diante do exposto compreendemos que a concepção socialista de homem e a formação humana requer um amplo debate em torno do tema. Devido a proeminência do assunto é necessário uma discussão aprofundada no movimento do real in lócus com docentes, discentes, comunidade escolar, universidade, movimentos sociais, partidos políticos, visando a transformação da consciência dos homens, tanto nos aspectos políticos como nos tópicos pedagógicos. Construindo nesse sentido, uma perspectiva crítica de educação comprometida com as tarefas de formar o novo homem e uma nova sociedade livre do modo de produção vigente. Entendemos que a escola em seu nicho isolada não conseguirá alcançar a práxis pedagógica e a superação do sistema. Porém, a escola é contraditória, é um importante espaço e instrumento na sua essência fundada para a aprendizagem, instrução, aquisição e socialização do conhecimento, assim como espaço para as lutas da humanidade.

Em meio as suas contradições a escola é um importante lugar para a conscientização política. E é por isso que Makarenko e Pistrak atribuem o devido destaque a escola e a educação por entenderem que é também através da escola e dos processos educativos em seus variados espaços que a juventude e a comunidade na concepção socialista aprendem e formam uma consciência crítica e política. Aprendem a reivindicar seus direitos políticos e sociais, aprendem a participar da vida da comunidade. Aprendem que a escola não é o único local em que se aprende, a aprendizagem no sentido crítico e socialista se dá também e principalmente nos movimentos sociais, nas lutas, nas tarefas políticas.

Nessa perspectiva teórica, o trabalho coletivo para formar o novo homem, uma nova sociedade, o novo espírito coletivo de homem, de mulheres é supervalorizado na práxis de Makarenko e Pistrak. A coletividade tanto para Makarenko como para Pistrak são indispensáveis para a formação do novo homem e do educador socialista, abarcando

\begin{tabular}{|l|l|l|l|l|} 
Revista Dialectus & Ano 1 & n. 1 & Julho-Dezembro 2012 & p. 271-283 \\
\hline
\end{tabular}




\section{DIÁLOGOS SOBRE FORMAÇÃO HUMANA E FORMAÇÃO...}

Lucíola Andrade Maia

também uma educação popular. Que a educação, a escola, a universidade, a comunidade sem trabalhar seus problemas em coletividade não se desenvolverá a contento pois, nos princípios socialistas, uma das características principais é a coletividade, inclusive a propriedade coletiva dos meios de produção tendo seus desdobramentos práticos e teóricos na formação da humanidade, da sociedade e particularmente na construção do educador ancorado nesses pressupostos.

Ademais, a compreensão de coletividade em Pistak (2009) é também o lado da luta pelo desenvolvimento material de novas formas sociais acolhedoras tanto do homem no sentido de indivíduo, como dos coletivos; novas formas sociais não excludentes dos outros indivíduos, o que pode ser obtido pela superação das relações sociais capitalistas, traçadas pelo exercício do individualismo e da competição. Diante da explanação e do debate da atualidade do socialismo no século XXI, ficam algumas indagações: quais as principais dificuldades que os homens enfrentam para desenvolver um trabalho coletivo coeso e coerente visando a superação do atual sistema? Quais os problemas elencandos para a convivência em coletividade, seja na escola, na universidade, nos movimentos sociais, nos partidos políticos buscando as utopias e a transcendência?

Quais as principais questões trabalhadas objetivando a superação e do individualismo e da competição tão praticada pelos homens capitalistas? Sabemos que esses são alguns dos grandes desafios que os homens verdadeiramente comprometidos com a transformação da sociedade precisam enfrentar, mais ainda sabemos que esse é um processo em construção, a construção da utopia revolucionária.

A organização coletiva e solidária da sociedade é um dos maiores legados das experiências de Makarenko e Pistrak, como de diversas lutas realizadas a favor da emancipação humana. Essa herança torna-se fundamental para que possamos encontrar as respostas às perguntas do inicio de nossa reflexão acerca de que tipo de homem e de sociedade necessitamos. Com essas reflexões aprendemos que o homem novo somente poderá existir com o exercício da práxis transformadora, fundada na organização consciente, solidária, autônoma livremente associado ao modo de produção socialista.

\section{Referências Bibliográficas}

CAPRILES, René. MAKARENKO - O nascimento da pedagogia socialista. São

\begin{tabular}{|l|l|l|l|l|}
\hline Revista Dialectus & Ano 1 & n. 1 & Julho-Dezembro 2012 & p. 271-283 \\
\hline
\end{tabular}


Paulo: Scipione, 1989.

FERNANDES, Florestan. Em Busca do Socialismo - últimos escritos e outros textos, São Paulo: Xamã, 1995.

FREIRE, Paulo. Conscientização. São Paulo: Moraes, 1980. ; MACEDO, Donaldo. Alfabetização: leitura do mundo, leitura da palavra. Rio de Janeiro: Paz e Terra, 1990.

FROM. Eric. Conceito marxista do homem. Rio de Janeiro: Zahar Editores, 1964.

GRAMSCI. Antonio. Concepção dialética da história. Rio de Janeiro: Civilização Brasileira, 1978.

Brasileira, 1980.

Os intelectuais e a organização da cultura. Rio de Janeiro: Civilização

KOSIK, Karel. Dialética do concreto. Rio de Janeiro: Paz e Terra, 1976.

LENIN, Vladimir Ulianov. Que fazer? São Paulo: Hucitec, 1988.

MAIA, Lucíola Andrade. Mística, educação e resistência no movimento dos semterra. Fortaleza: Edições UFC, 2008.

CCB Editora, 2010.

; PINHEIRO, Carísia Maia. Mestres da educação socialista. Fortaleza:

MANACORDA, Mario Alighiero. História da educação: da antiguidade aos nossos dias. São Paulo: Cortez, 2000.

. Marx e a pedagogia moderna. 3. ed. Tradução de Newton Ramos de Oliveira; Revisão técninca de Paolo Nosella. [s.1]: Cortez Editora, 2000.

MAKARENKO, Anton Semionovich. Conferências sobre educação infantil. São Paulo: Moraes, 1981.

. Poema pedagógico. 2. ed. São Paulo: Brasiliense, 1987. V.1.

. Poema pedagógico. 2.ed. São Paulo: Brasiliense, [s. d]. V.2.

. Poema pedagógico. 2. ed. São Paulo: Brasiliense, 1991. V.3.

. Problemas da educação escolar. Moscou: Editora Progresso, 1986.

MARX, Karl \& ENGELS, Frederich. Textos sobre educação e ensino. 2. ed. São

Paulo: Moraes, 1992.

MESZÁROS, István. Para além do capital. Campinas: Boitempo Editorial, 2002.

\begin{tabular}{|l|l|l|l|l|} 
Revista Dialectus & Ano 1 & n. 1 & Julho-Dezembro 2012 & p. 271-283 \\
\hline
\end{tabular}


2003.

. A teoria da Alienação em Marx. São Paulo: Boitempo Editorial,

Editorial, 2005.

A Educação Para além do Capital. São Paulo: Boitempo

PITRAK, M. Moisey (Org). A Escola-comuna. São Paulo: Expressão Popular, 2009.

Fundamentos da escola do trabalho. São Paulo: Expressão Popular, 2002.

VÁZQUEZ, Adolfo Sánchez. Filosofia da práxis. São Paulo: Expressão Popular, 2007. 